\title{
THE
}

$9-19-2018$

\section{Design Features of a Professional Development Program in Digital Literacy}

Renee Hobbs

Harrington School of Communication and Media, University of Rhode Island, hobbs@uri.edu

Julie Coiro

University of Rhode Island, jcoiro@uri.edu

Follow this and additional works at: https://digitalcommons.uri.edu/com_facpubs

The University of Rhode Island Faculty have made this article openly available.

Please let us know how Open Access to this research benefits you.

This is a pre-publication author manuscript of the final, published article.

Terms of Use

This article is made available under the terms and conditions applicable towards Open Access

Policy Articles, as set forth in our Terms of Use.

\section{Citation/Publisher Attribution}

Hobbs, R. \& Coiro, J. (2018). Design features of a professional development program in digital literacy. Journal of Adolescent and Adult Literacy. DOI: 10.1002/jaal.907 


\title{
CITE AS:
}

\section{PRE-PUB COPY}

Hobbs, R. \& Coiro, J. (2018). Design features of a professional development program in digital literacy. Journal of Adolescent and Adult Literacy. DOI: doi: 10.1002/jaal.907

\section{Design Features of a Professional Development Program in Digital Literacy}

\author{
Renee Hobbs and Julie Coiro
}

Teaser Text: To advance the digital literacy competencies of educators, create opportunities for them to reflect on their motivations for using digital media, make collaborative inquiry a substantive component of the hands-on learning experience, and create opportunities to put teachers and learners (not machines) at the center of attention.

\begin{abstract}
This essay introduces readers to three design features of the University of Rhode Island's Summer Institute in Digital Literacy (SIDL), a 42-hour week-long professional learning experience in digital literacy for educators, librarians, college faculty and other adult learners. The program is explicitly designed to (a) promote reflection on one's motivations for advancing digital literacy; (b) deepen appreciation for collaborative inquiry; and (c) focus on how educators and learners (not machines) personalize learning. Evidence of how these themes are developed through practice illustrates the design philosophy that is embedded in the program. Digital media platforms, texts and technologies enable pedagogical practices that put learners and teachers at the center of an increasingly networked social world but these approaches also require respect for diverse perspectives, deliberative dialogue and collaborative inquiry to bring them into the mainstream educational practice of schools, libraries, universities and communities.
\end{abstract}

We had been together for five years before we decided to celebrate. And we didn't celebrate by having a five-year birthday party - instead, we wrote this paper to reflect and wonder and consider what we have built together with the help of many willing hands, including 25 faculty colleagues from around the country and around the world.

Every summer since 2013, Renee and Julie (the authors) have worked with K-12 educators, youth media professionals, school leaders, college faculty and librarians who share our interests in the intersection of education, information, communication and media studies. Through designing, implementing, and assessing a professional development program, we have conceptualized digital literacy in relation to the needs of experienced adult learners whose motives for wanting to incorporate digital texts, tools and technologies into the curriculum vary widely. Our collaborative work in digital literacy is thus located in pragmatic action focused on professional development.

Over time and as a result of sustained exposure to the many more than 500 adult learners who have participated in an intensive professional development program at the University of Rhode Island's Summer Institute in Digital Literacy, we have collaboratively built a joint understanding of 
digital literacy education. In developing the program, we have taken time to consider the interplay between elementary, secondary, higher education and informal learning contexts, and our approach spans the disciplines of both literacy education and communication/media studies.

A little context may be useful here: The first URI Summer Institute in Digital Literacy was first held in July of 2013 and the program has run annually since then. As a week-long, 42-hour professional development program, the program has enrolled participants from 25 states and 15 countries. Each year between 60 to 120 people have enrolled in the program. The program was one of three professional development programs showcased in the U.S. Department of Education's National Educational Technology Plan (U.S. Office of Educational Technology, 2016). The program has included keynote lectures from authors, educators and activists including Douglas Rushkoff, Howard Rheingold, Joyce Valenza, Chris Lehman, Dan Gillmor and Nuala and Len Cabral.

During the week, participants select from among 40 workshops where they can experiment with digital platforms, tools and texts and learn about research and program development in digital literacy. Each afternoon, participants collaborate with a partner to develop a Design Studio project that is relevant to their needs, showcasing this work to their peers at the end of the week. A variety of faceto-face and online learning activities encourage collaboration and metacognitive reflection on one's identity as an educator, learner, team member and leader. In the summer and extending all year, the learning community shares ideas and information using the hashtag \#digiURI on Twitter, Google Plus, Facebook and other platforms. The Media Education Lab also hosts free online webinars that showcase the work of former program participants, enabling "everyone to learn from everyone" long after the professional development program has ended.

Three important program design features of the Summer Institute in Digital Literacy include a focus on (a) promoting reflection on one's motivations for advancing digital literacy; (b) deepening appreciation for collaborative inquiry; and (c) focusing on how educators and learners (not machines) personalize learning. For readers of $J A A L$ who are involved in advancing digital literacy education through creating, implementing and assessing professional development programs for in-service or pre-service teachers or other adult learners, we invite you to consider how these three features of the Summer Institute in Digital Literacy may be valuable to you.

In this essay, we will show how these features have contributed to the perceived relevance and value of the professional development program. If you are working to help educators or adult learners work with one another to advance their own and students' digital literacies, these concepts may apply in your own work. By sharing our experience in designing learning environments for educators, librarians, youth media professionals and higher education faculty, we seek to reflect on our choices and strategies. But before we offer insight on these themes, we briefly review the theoretical frames that have shaped our inquiry.

\section{Theoretical Frames}

We define digital literacy as an expanded conceptualization of literacy that is responsive to the ongoing changes in information and communication technologies that are part of everyday life. As we see it, digital literacy education involves a set of competencies connected to reading and authorship situated in a classroom culture of teaching practices that value, model, scaffold, and facilitate aspects of inquiry, analysis, collaboration, creation, reflection, and social action (Buckingham, 2007; Hobbs, 2010a; Leu, Kinzer, Coiro, \& Cammack, 2004).

Our approach to digital literacy draws from a multidisciplinary lineage in education, communication, social sciences, and the humanities. Theoretically, our work builds upon scholarship in education, media studies and cultural studies, which conceptualizes learning as a process of inquiry 
and discovery (Bruner 1960; Dewey, 1900) where meaning-making is an active process (Ogden \& Richards, 1923; Hall, 1980) that involves examining not only the form and content of messages but also the affordances and limitations of the technologies used to create them (McLuhan, 1964). We see literacy practices as situated, contextual cultural practices (Vygotsky, 1978) that use multimodality (Kress, 2010) to activate multiple modes of knowing (Gardner, 1983). We further recognize that media and technology constitute a cultural environment and serve as the culture's primary storyteller (Gerbner, 2009). Digital participation promotes personal and social reflection, personal autonomy and collaboration (Jenkins et al, 2006). These outcomes support the practice of literacy by reshaping relationships between teacher and learners and between learners and their culture (Freire, 1970).

Digital media offers transformative implications for pedagogical practices that put learners and teachers at the center of an increasingly networked social world (Aspen Institute, 2014). Digital media make it easy for learners to have choice and voice in ways that make student-directed learning a reality for every learner (Coiro, Kiili, \& Castek, 2017). Thus, digital literacy embodies Dewey's dream of learning as focused on real-world problem-solving that awakens students to their democratic social responsibilities; learning for which knowledge and deliberative dialogue are used to understand and address problems we find in our neighborhoods, our communities and in our world, helping to create a more just and equitable world.

\section{Motivations Matter}

The first design feature of the Summer Institute in Digital Literacy is focused on reflection about one's motivations by essentially asking, "Why are you here?" When we first started using the term digital literacy to refer to our collaborative work in professional development, we began by asking participants to define the term for themselves, asking, "What does digital literacy mean to you?" From this, we discovered that digital literacy was an umbrella concept: people define and articulate digital literacy in different ways, depending on their disciplinary background, identity and life experiences. As a result, we decided we didn't need a single definition - we could embrace a multivocal perspective on the topic.

Adult learners bring a variety of different motivations into play when participating in a professional development learning community. When participants reflect on their own reasons for exploring the topic of digital literacy, it also helps clarify one's priorities. Respecting and honoring this diversity sets the stage for co-learning to occur.

As co-authors, we have experienced this ourselves when it comes to defining digital literacy, as Julie's focus on online reading comprehension and Renee's focus on media literacy education lead us to difference nuances in our understanding of these ideas. The scholarly community in digital literacy has long-recognized the variety of different purposes, goals and motivations (Alexander, Becker, Cummins, \& Giesinger, 2017). Indeed divergent perspectives on digital literacy are common. Various approaches to digital literacy have drawn on scholarship from semiotics and multimodality (Kress, 2010), interpretation, meaning-making and issues of representation (Hall,1980), the political economy of digital platforms in education and issues of data privacy (Bulger, 2016), just to name a few. We see such diversity as a significant source of strength for the long-term future of digital literacy.

So rather than define digital literacy narrowly in terms of identifying skills, competencies, processes or habits of mind, we begin the Summer Institute by asking people to explain why they have chosen to attend. We discover that participants have differing motivations and different reasons for embracing the term, digital literacy. Because motivation situates human action in relation to lived experience and social context (Ryan \& Stiller, 1991), we recognize that teachers' motivations for digital learning have a strong influence on their actual use of digital media and technology in schools. 
Teachers decide whether, what and how technology gets used in classrooms (Conway \& Zhao, 2001). When teachers are motivated, they make greater use of digital tools and technologies in their classrooms (Karsenti, Villeneuve, \& Goyer, 2006).

But since discussions of digital literacy may sometimes omit consideration of the complex love-hate relationship that educators have in responding to the rise of mass media, popular culture, digital media in society (Hobbs, 2017), we have devised a strategy that helps put it center stage, one that involves reflection and dialogue on empowerment and protection in relation to one's motivations for digital literacy and digital learning.

Through our work at the Summer Institute in Digital Literacy, we have discovered that adults come to an interest in digital literacy with a complex and nuanced set of pre-existing attitudes and beliefs about technology, media, education and learning. For example:

- Some educators, librarians and parents see digital media's ubiquitous presence in the home as interfering with early childhood development; others see digital media as a means to engage learners in developing skills that transfer between home and school.

- Some fear that digital devices are limiting practices of reading and writing while others see it as extending and deepening these practices.

- Some fear that the social skills of children and young people are being compromised or shortchanged, while others see young people engaged in sophisticated social discourses that reflect and shape their personal and social identity.

- Some see the rise of so-called "fake news" as resulting from the lack of critical examination of the credibility of online information sources; others see the value of blogs, videos, and other online information sources as vital resources for developing knowledge and skills.

- Some believe that social media, laptops and cell phones are a significant distraction from student learning; others recognize the value of using these devices to support academic work, build transferable career skills and engage in social, civic or political action.

Such diverse motivations for digital literacy are rooted in a dialectic of empowerment and protection (Hobbs, 2010a; 2010b). Most people have a complex mix of attitudes, including concerns about how digital media and technology introduces a variety of risks and potential harms to individuals or society while also holding more positive beliefs about the value of digital media for learning purposes.

Teacher motivations for digital learning have been identified using the dialectic of empowerment and protection in relation to six key theoretical frames, including attitudes toward (1) technology tools; genres and formats; (2) message content and quality; (3) community connectedness; (4) texts and audiences; (5) media systems; and (6) learner-centered focus (Hobbs \& Tuzel, 2017).

Over the years, the Summer Institute in Digital Literacy has attracted a diverse array of educators, librarians, school leaders, youth media professionals and college faculty. Depending upon their professional backgrounds, interests and prior experiences, participants may have different perspectives about media systems and institutions, different levels of focus on the content or quality of digital texts, or more or less sensitivity towards learner needs.

For these reasons, at the opening session, we begin the program by first inviting participants to reflect on the different digital learning motivation profiles shown in Figure 1 and Appendix A and then we build hands-on co-learning experiences that help them reflect upon and become aware of their own motivations. Figure 1 displays the 12 Digital Learning Motivation Profiles that we use at the Summer Institute in Digital Literacy. Appendix A offers an informal description of the Digital Learning Motivation Profiles that readers can use to self-identify motivations. A 48-item online quiz which has 
been used as a research tool is also available at www.quiz.discovermedialiteracy.com to deepen your reflection on own your motivations and consider why digital literacy is important to you.

Right from the start, we ask participants to discuss their existing beliefs and identify the conceptual themes of most importance to them. As they identify the motivations that align with their beliefs and values, they get acquainted with other participants who share some of the same values. Then they meet someone who has a different primary motivation to discuss their different perspectives. Pragmatically, this process facilitates the "meet-and-greet" process and helps people appreciate the diversity of perspectives and motivations among both the participants and faculty.

During the week, we have observed that participants get used to asking, "Why are you using this digital tool?" and they also seem to gain more precision in talking about why they are using others, resources, texts, technologies and platforms. The Digital Learning Motivation Profile provides participants with a vocabulary (rooted in the idea of a horoscope) that supports reflection and social interaction about the different motivations of educators across the K-20 spectrum in both formal and informal contexts. We suspect that this activity may also enhance the quality of peer-to-peer collaboration.

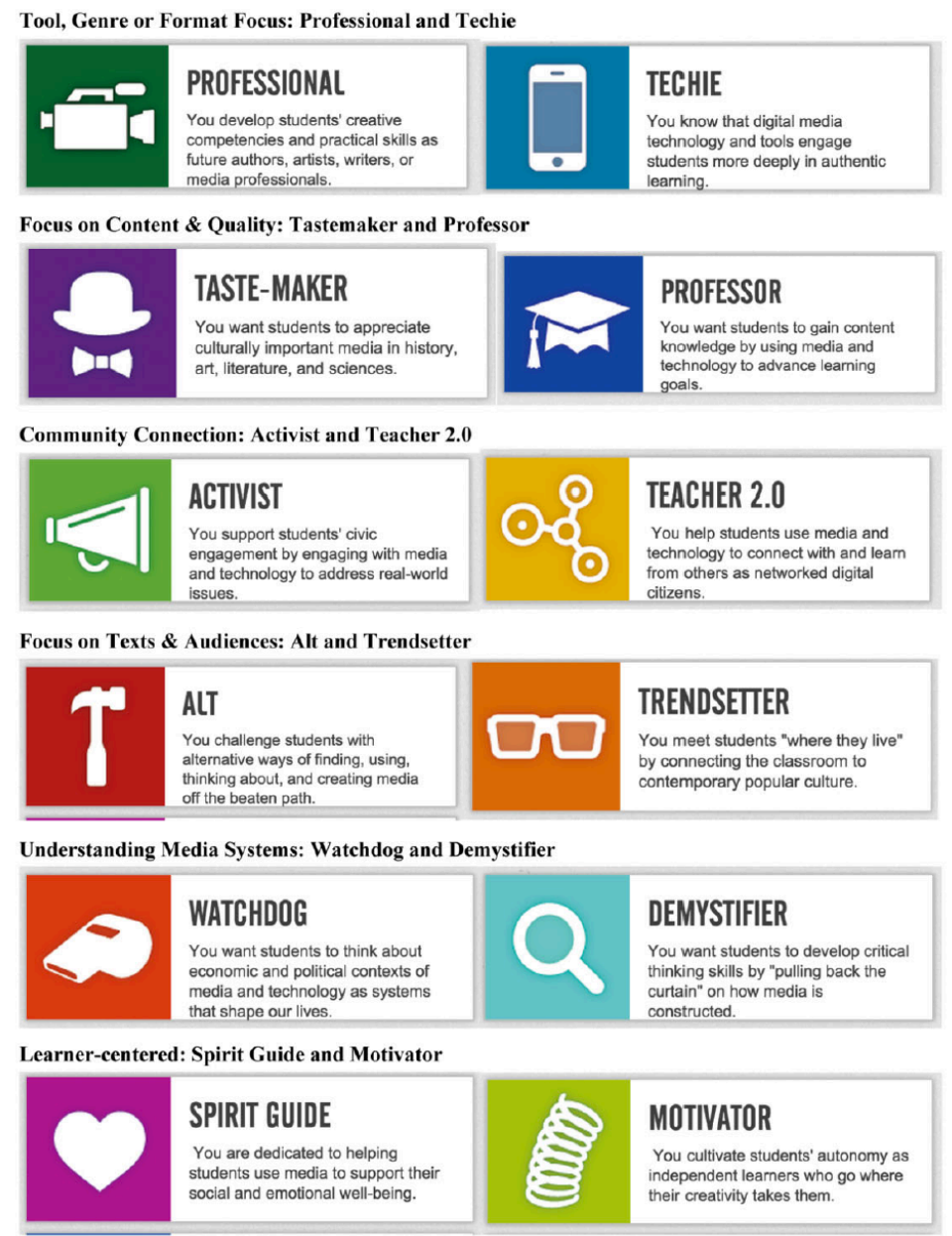

Figure 1

Digital Learning Motivation Profiles 
One of the reasons why we came to care about identifying and valuing differences in the differential motivations of adult learners enrolled in the Summer Institute in Digital Literacy is because we recognized differences in our own motivations as faculty collaborators. Among the 12 digital learning motivations profiles shown on Figure 1, Julie might be identified as a "professor" because of her intentional strategy of using digital texts in ways that align lessons with a clear connection to academic standards and learning outcomes. With her students she is also a "spirit guide" because of her sensitivity to student-teacher relationships and the socio-emotional dimensions of student engagement. Co-author Renee might be best identified as a "demystifier" because, when it comes to digital learning, she focuses on helping learners explore "how" and "why" questions that examine the constructed nature of media messages, especially in relation to the political economy of mass media and popular culture. Renee might also be identified as an "activist" because of her enduring passion for fostering democratic participation through social action and her interest in student voice as a catalyst for improving their communities and the world. Our productive collaboration has been fueled by "the power of two" which has enabled us to appreciate both the similarities and differences in our respective approaches to the topic both as researchers and teachers (Hobbs \& Coiro, 2016).

\section{Collaborative Inquiry Learning}

The second design feature of the Summer Institute in Digital Literacy centers on inquiry and collaborative learning. Digital media offers important, transformative implications for pedagogical practices that put learners and teachers at the center of an increasingly networked social world (Aspen Institute, 2014). That's one reason why digital literacy is empowering. For example, the many digital platforms available now offer users many choices of information and entertainment, many different forms of expression and creativity; and many different opportunities for social interaction and engagement. They provide rich opportunities for freedom, autonomy and exploration for learners themselves.

Digital literacy learning experiences also build people's confidence. Learners increase agency through voice and choice when they get more frequent opportunities to ask their own questions, choose their own texts, or select from a wide range of topics. Students advance agency with more time to talk through their interpretations and share meanings together. By choosing how to creatively express ideas and create media, as well as explore different ways of taking social action, learners may explore their identities as citizens who can improve their communities and society.

We have found that educators need to directly experience collaboration and inquiry as a process of messy engagement and problem-solving in order to appreciate the cognitive, social and emotional dimensions of digital literacy as they consider how to best support their own students (Hobbs, 2017).

Because inquiry and collaborative learning are key design features of the Summer Institute in Digital Literacy, participants are encouraged to work collaboratively on a Design Studio project. Participants have approximately 10 hours during the week to develop a Design Studio project with a peer. To support the teachers, librarians and college faculty who attend the Summer Institute in Digital Literacy, we developed the personal digital inquiry model of digital and media literacy (PDI-DML), which offers substantial opportunities for increase voice and choice for both teachers and learners. Figure 2 shows the visual model we have developed to describe this learning experience. In Design Studio, participants experience collaborative inquiry as they wonder and discover, collaborate and discuss, create and take action, and analyze and reflect. They access, analyze, create, reflect and take 
action using the power of communication and information. For educators to develop competencies in teaching digital literacy, they must first experience this process as learners themselves.

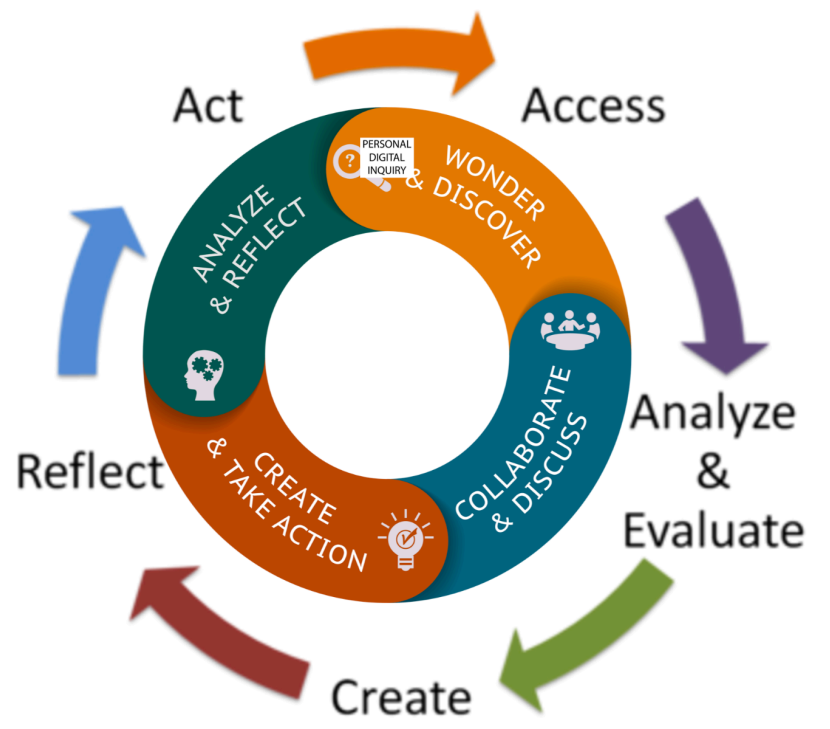

Figure 2

Personal Digital Inquiry in Digital and Media Literacy (PDI-DML)

We feel that it is important to emphasize that Design Studio, with its collaborative peer-to-peer learning approach is not a supplement or a mere element of the program; this feature is baked into the fundamental elements of the program design (Hobbs \& Coiro, 2016). Participants access ideas and information from short workshops that feature new digital platforms, texts and technologies to stimulate their thinking and skills Then they use time in Design Studio to synthesize and apply information from among the many different hands-on learning experiences and conversations they have had during the week. By working with a partner, the complexity of their work is multiplied and the importance of choice, strategy and sequence become more important. By working with a partner in Design Studio, participants spend a lot of time talking about the decisions they make as educators.

As a result of directly experiencing inquiry and collaboration as a learning process themselves, many participants have been inspired to take on the challenges of inquiry and collaboration in their workplaces, schools and communities. Previous participants have documented their Design Studio projects as they implemented them in their schools and communities. Some have describe how they used collaboration and inquiry to make substantive change in their own schools and communities on the SIDL blog, entitled, "From PD to Practice," developed by Stephanie Branson, Kara Clayton and Amanda Murphy. The blog is available: https://digiuri.wordpress.com/blog/.

The opportunity to publish and share curricular and creative work further helps shift participant mindsets towards leadership, which we have formally aimed to develop through the Graduate Certificate in Digital Literacy, which is a 12-credit graduate certificate program that builds upon the Summer Institute in Digital Literacy and helps advance leadership competencies. When adult learners directly encounter (and not just learn about) digital literacy pedagogies, a deeper sense of agency and heighten sense of personal and social accountability may develop. With appropriate leadership skills in place and a supportive organizational climate, many educators can take a leadership role in how digital literacy instructional practices become normative with a school building or community. 


\section{Digital Literacy and Personalized Learning}

The third design feature of the Summer Institute in Digital Literacy has emerged in relation to the political and economic context in which the topic of digital literacy has developed in the education marketplace. School districts all around the world are facing many pressures to "go digital." At this historical moment, the rise of the concept of digital literacy must be understood in relation to those many venture capitalists have invested more than $\$ 2.3$ billion in educational technology companies since 2010, with over $\$ 1$ billion raised in 2016 alone (Wan, 2016). The concept of digital literacy has been supported by educational technology experts, venture capitalists, and this momentum is fueled by the infusion of one-to-one laptop implementation in school districts along with the increasing ubiquity of digital devices at home, work and school. Teacher education is often the last priority.

These circumstances have had an impact on our work. Although we are highly supportive of digital innovation in the educational technology sector, we reject efforts that de-professionalize teachers through blended learning programs where learning practices and content are embedded in and delivered through software algorithms. We believe that teachers are best suited to offer adaptive learning to students; we are concerned about the scope of the hype and the lack of research in the many claims made about personalized learning through technology, digital content and software tools.

Too many schools have embraced a device-oriented approach to technology integration. In some schools, digital platforms have become glorified worksheet delivery systems. Our concerns about this has led us towards a distinct stance in relation to personalized learning, a term sometimes used to describe technology-enabled learning with varying degrees of tailoring or customization of a learning experience through platform software or apps. The customization occurs through the use of big data, which captures student keystroke data and uses programming algorithms to propose new tasks. At the present time, little independent research has been conducted to demonstrate the value of such technology-driven personalization for learners. As Bulger (2016) points out, there are no established standards for describing or evaluating the extent to which a learning experience is personalized.

Rather than re-training teachers to monitor the process of students moving through a series of digital playlists and administer online assessments, the Summer Institute in Digital Literacy is designed to foster teacher agency so that educators gain confidence in designing their own lesson plans and instructional units for inquiry-based digital learning. We see teachers as eminently capable of supporting and scaffolding student learning through inquiry and collaboration. Learners themselves, at any age, are eminently capable of creating media to express and demonstrate their knowledge and skills. We also see both teachers and learners as civic actors, willing to use the power of communication and information to advocate for the social and political change they value most.

It's important to approach digital media platforms, texts and technologies with curiosity. We invite educators to identify the potential useful qualities as well as unintended consequences and ideologies that are embedded in all digital media. Informed skepticism about the wonders of educational technology are needed now more than ever. For these reasons, our pragmatic focus on teacher agency and professional development may help us better understand how educators take responsibility to intentionally design robust learning environments for inquiry-based learning in digital literacy.

In this essay, we've explained how the Summer Institute in Digital Literacy prioritizes (a) reflection on one's motivations for advancing digital literacy; (b) practices of inquiry and collaborative learning; and (c) the exploration of how educators and learners (not machines) personalize learning. 
We invite you to consider applying these three design features from the Summer Institute in Digital Literacy to any of the professional development programs you create, implement and assess.

Undoubtedly, digital literacy is a moving target for everyone in the education sector and it will continue to evolve in the years to come. Before we reach our $10^{\text {th }}$ birthday as co-directors of the Summer Institute in Digital Literacy, further work will be needed as we drill down to understand some of the many complex dimensions of this work. However, as the concept of digital literacy continues to evolve, we hope that its roots in literacy remain strong, for we believe that the sharing of meaning through symbolic expression is a fundamentally human way of learning for a lifetime.

\section{TAKE ACTION!}

1. Reflect on your own motivations and those of the people you work with. Review the Digital Learning Motivations Profiles in Appendix A to consider which profiles best match your passions, interests and concerns. Take the online quiz to get more feedback on your motivation profile at http://quiz.discovermedialiteracy.com/ Consider how your motivations affect the choices you make about what and how you teach and how you learn. How may diverse motivations among a team or unit enhance high-quality learning opportunities?

2. Consider how you experience and enact choice and voice. Then consider how you and your students experience agency. To what extent do you (and your students) have opportunities:

- to choose what instructional materials to use in class?

- to choose what topics to focus on in class?

- to document their learning using a range of digital media forms and tools?

3. Discuss how educational technology and corporate interests are defining personalized learning. Discuss: what are the consequences of a embracing a device-oriented approach to technology integration? For example, how may the use of digital playlists foster teacher agency? What might be some unintended negative consequences?

\section{MORE TO EXPLORE}

- Media Education Lab (2015). Discover Media Literacy. What's Your Motivation? www.discovermedialiteracy.com

Take the Digital Learning Motivations Horoscope quiz to find out which of the 12 motivational profiles best matches your motivations for advancing digital and media literacy in the context of your role.

- Media Education Lab (2017). Grandparents of Media Literacy. www.grandparentsofmedialiteracy.com

Discover the multidisciplinary roots of digital and media literacy education by learning more about the scholars and writers whose ideas influenced the field in this crowdsourced interactive gallery. 


\section{REFERENCES}

Alexander, B., Becker, S. A., Cummins, M., \& Giesinger, C. H. (2017). Digital Literacy in Higher Education, Part II: An NMC Horizon Project Strategic Brief. The New Media Consortium. https://www.nmc.org/publication/digital-literacy-part-ii-an-nmc-horizon-project-strategicbrief/

Aspen Institute (2014). Learner at the Center of a Networked World. Aspen Institute Task Force on Learning and the Internet.

https://assets.aspeninstitute.org/content/uploads/files/content/docs/pubs/Learner-at-the-Centerof-a-Networked-World.pdf

Bruner, J. (1960). The process of education. Cambridge: Harvard University Press.

Bulger, M. (2016, July 22). Personalized Learning: The Conversations We're Not Having. Data and Society. https://datasociety.net/pubs/ecl/PersonalizedLearning_primer_2016.pdf

Buckingham, D. (2007). Digital media literacies: rethinking media education in the age of the Internet. Research in Comparative and International Education, 2(1), 43-55.

Coiro, J., Kiili, C., \& Castek, J. (2017). Designing pedagogies for literacy and learning through Personal Digital Inquiry. In F. Serafini \& E. Gee (Eds.), Remixing multiliteracies: Theory and practice from New London to New Times (pp. 119-233). New York: Teachers College Press.

Conway, P. \& Zhao, Y. (2001). From Luddites to Designers: Portraits of Teachers and Technology in Political Documents. Paper presented at the American Educational Research Association (AERA) annual meeting Seattle, WA, USA, April 10-14.

Dewey, J. (2017/1900). School and society. Chicago: University of Chicago Press. Project Gutenberg.

Freire, P. (1970/2006). Pedagogy of the oppressed. Translated by Donaldo Macedo. New York: Continuum.

Gardner, H. (1983). Frames of mind: The theory of multiple intelligences. New York: Basic.

Gerbner, G. (2009). The Electronic Storyteller. [Video interview.] Northhampton, MA: Media Education Foundation.

Hall, S. (1980). Encoding/Decoding. In Culture, Media, Language, edited by S. Hall, D. Hobson, A. Lowe, P. Willis $(128-139)$. London: Hutchinson.

Hobbs, R. (2017). Approaches to teacher professional development in digital media literacy education In B. De Abreu, P. Mihailidis, A. Lee, J. Melki \& J. McDougall (Eds). International Handbook of Media Literacy Education (pp. 88 - 113). New York: Routledge.

Hobbs, R. (2010). Digital and Media Literacy: A Plan of Action. Washington, D.C.: John S. and James L. Knight Foundation and Aspen Institute.

Hobbs, R. (2010b). Empowerment and protection: Complementary strategies for digital and media literacy education in the United States. Formare, 70. 1 - 17. Rome, Italy. http://formare.erickson.it/wordpress/en/2010/empowerment-e-protezione-strategiecomplementari-per-la-digital-e-media-literacy-negli-stati-uniti/

Hobbs, R. \& Coiro, J. (2016). Everyone learns from everyone: Collaborative and interdisciplinary professional development in digital literacy. Journal of Adolescent and Adult Literacy 50(2), 1 - 7. doi:10.1002/jaal.502

Hobbs, R. \& Tuzel, S. (2017). Teacher motivations for digital and media literacy: An examination of Turkish educators. British Journal of Educational Technology 48(1), 7 - 22.

DOI: $10.1111 /$ bjet.12326 
Ito, Mizuko, Kris Gutiérrez, Sonia Livingstone, Bill Penuel, Jean Rhodes, Katie Salen, Juliet Schor, Julian Sefton-Green, and S. Craig Watkins. (2013). Connected Learning: An Agenda for Research and Design. John D. and Catherine T. MacArthur Foundation: Digital Media and Learning Research Hub.

Jenkins, H., Purushtoma, R., Weigel, M., Clinton, K. \& Robison, A. (2006). Confronting the Challenges of a Participatory Culture: Media Education for the $21^{\text {st }}$ Century. John D. and Catherine T. MacArthur Foundation. Cambridge: MIT Press.

Karsenti, T., Villeneuve, S. \& Goyer, S. (2006, March). The Impact of Motivation on Prospective Teachers' Use of Information and Communication Technologies (ICTs). Paper presented at the International de la Society of Information Technology in Teacher Education, Orlando, Florida.

Kress, G. (2010). Multimodality. London: Routledge.

Leu, D. J., Kinzer, C. K., Coiro, J. L., \& Cammack, D. W. (2004). Toward a theory of new literacies emerging from the Internet and other information and communication technologies. Theoretical Models and Processes of Reading, 5(1), 1570-1613.

McLuhan, M. (1964). Understanding media: The extensions of man. New York: McGraw Hill. Ogden, C.K. \& Richards, I. A. (1923/1989). The meaning of meaning. New York: Harvest HBJ.

Ryan, R.\& Stiller, K. (1991). The social context of internalization: Parent and teacher influence on autonomy, motivation and learning In R. Pintrich and M. Maehr (Eds) Advances in motivation and achievement. Volume 7. Goals and Self Regulatory Processes. (pp. 115 - 149). Greenwich CT: Jai Press.

U.S. Office of Educational Technology, Department of Education (2016). National Educational Technology Plan. https://tech.ed.gov/netp/

Vygotsky, L. (1978). Mind and society. Translated by Michael Cole. Cambridge, MA: Harvard University Press.

Wan, Tony (2016, December 31). Ka’Ching! 2016 US Edtech Funding Totals \$1 Billion. Ed Surge. http://bit.ly/2o0aJPHd 
Tool, Genre or Format Focus: Professional and Techie

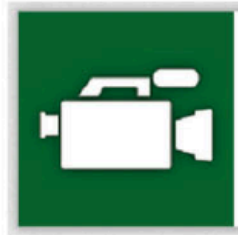

\section{PROFESSIONAL}

You develop students' creative competencies and practical skills as future authors, artists, writers, or media professionals.

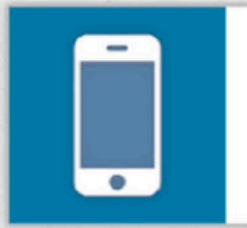

\section{TECHIE}

You know that digital media technology and tools engage students more deeply in authentic learning.

Focus on Content \& Quality: Tastemaker and Professor

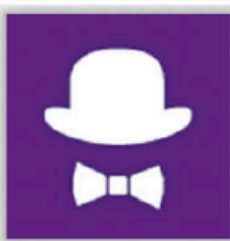

\section{TASTE-MAKER}

You want students to appreciate culturally important media in history, art, literature, and sciences.

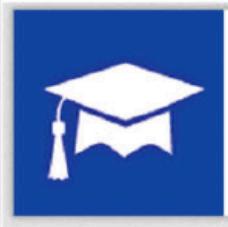

\section{PROFESSOR}

You want students to gain content knowledge by using media and technology to advance learning goals.

Community Connection: Activist and Teacher 2.0

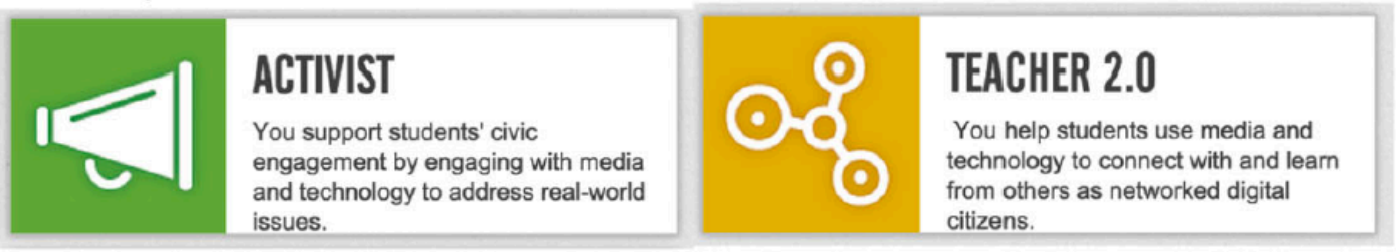

Focus on Texts \& Audiences: Alt and Trendsetter

ALT
$\begin{aligned} & \text { You challenge students with } \\ & \text { alternative ways of finding, using, } \\ & \text { thinking about, and creating media } \\ & \text { off the beaten path. }\end{aligned}$

Understanding Media Systems: Watchdog and Demystifier

WATGHDOG
$\begin{aligned} & \text { You want students to think about } \\ & \text { economic and political contexts of } \\ & \text { media and technology as systems } \\ & \text { that shape our lives. }\end{aligned}$

Learner-centered: Spirit Guide and Motivator

SPIRIT GIIIEE
$\begin{aligned} & \text { You are dedicated to helping } \\ & \text { students use media to support their } \\ & \text { social and emotional well-being. }\end{aligned}$

Figure 1

Digital Learning Motivation Profiles 


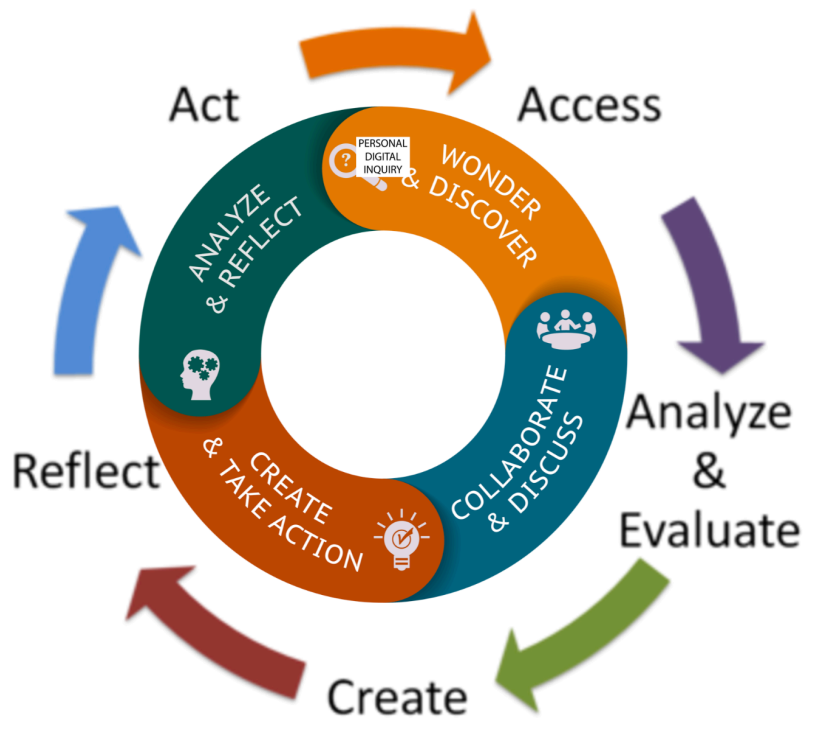

Figure 2

Personal Digital Inquiry in Digital and Media Literacy (PDI-DML) 
Appendix A

DIGITAL LEARNING MOTIVATIONS PROFILE

Which of the following profiles best aligns with your priorities and values?

\section{TASTEMAKER}

You want to broaden your students' horizons. You know that digital media can increase students' exposure to a wide variety of texts, ideas, people and experiences that deepen their understanding of history, the arts and sciences, culture and society. You know that a key component of students' future success in life will require them to draw from a variety of cultural sources both classical and popular.

\section{PROFESSOR}

You balance your interest in media and technology with a deep connection to academic content and standards. You want to be sure that media and technology are not used merely as bells-and-whistles, but to advance specific content knowledge and skills.

c

\section{ACTIVIST}

As an educator, you want to make society more just and equitable by promoting democratic participation. You use media and technology in the classroom as a catalyst for students to understand how they might have a voice in improving life in their communities and in the world.

\section{TEACHER 2.0}

You understand that participation in digital media and learning cultures requires flexibility to new formats, modes of expression, and participation in and out of school. You value media and technology tools for their power in helping people connect with others to tell and share their stories.

\section{DE-MYSTIFIER}

As an educator, you "pull back the curtain" to help students see how all forms of information and knowledge are constructed. You emphasize the practice of critical thinking, helping students ask good "how" and "why" questions.

\section{WATCHDOG}

You are a natural critical thinker, aware of how economic systems and institutions influence our everyday lives, particularly through the media and technology we use. You want your students and your peers to be more mindful of the ways that things are bought and sold. Who owns and controls the media content that we see, hear, read, and play with? You feel responsible for giving your students a "wake-up call" about the economic and institutional inner-workings of the technology tools and the world that surrounds them.

\section{MOTIVATOR}

You are an inspiration and a catalyst for your students' creative energy. Students who have never felt comfortable speaking up in class, participating in activities, or contributing to class dialogue find it easier to speak their mind when you're leading the classroom. You see your role as helping students be the best they can be. 


\section{SPIRIT GUIDE}

You are a listener. You have a dedication to the social and emotional well-being of your students, and do everything you can to help students understand themselves and their lives. Students likely find you trustworthy, and may even confide in you in ways that they do not with other people. You recognize that media and technology may affect how students deal with relationships that help them manage the highs and lows of life.

\section{TECHIE}

You have a passionate curiosity about new digital tools and like to be the first one to discover and use these tools. You experiment with how digital tools can promote learning and see much potential to engage students with the media and technology tools they love and use in their everyday lives.

\section{PROFESSIONAL}

You have high standards for your students' work, and you may be seen as the go-to media professional in your school. You know how to push your students to understand and emulate the conventions that are important to being taken seriously as a creative author, artist, writer or media professional. You may coproduce with your students or bring other authors, professionals or media-makers into your classroom to enrich the learning experience.

\section{ALT}

You are an inventive, perhaps "DIY," teacher. You're always ready to challenge students with alternative ways of finding, using, thinking about, and creating media. Whether you use open source or remix content, encourage students to start alternative clubs or magazines, or simply introduce students to information that's "off the beaten path," you broaden students' understanding of the many different types of content that are available through digital media.

\section{TRENDSETTER}

You're smart about pop culture and curious about kid culture. Maybe your own most-loved popular culture isn't too far removed from that of your students. You are inquisitive about the trends and hot topics that make up a crucial component of the fabric of your students' everyday lives. You want school culture to connect to the popular culture that students know and value. 